\title{
Redução do nível protéico da dieta, através da formulação baseada em aminoácidos digestíveis
}

\author{
Protein levels reduction of broilers in the initial phase \\ Lúcio Francelino Araújo ${ }^{1}$ Otto Mack Junqueira ${ }^{2}$ \\ Cristiane Soares da Silva Araújo ${ }^{3}$
}

\section{RESUMO}

Um experimento foi conduzido para estudar a redução do nível protéico da dieta, através da formulação baseada em aminoácidos digestíveis, de frangos de corte na fase inicial. Foram utilizados 800 pintos machos, Cobb, os quais foram pesados e distribuídos em delineamento inteiramente casualizado, com 4 tratamentos $(22 \%, 20 \%$ e $18 \%$ PB formuladas com aminoácidos digestíveis e 1 tratamento testemunha com 22\% PB e formulada com aminoácidos totais), com 4 repetições de 50 aves cada. Foram avaliados o ganho de peso, consumo de ração e conversão alimentar. Quando as aves foram alimentadas com a dieta referência, obtiveram, estatisticamente $(P>0,05)$, o mesmo ganho de peso e conversão alimentar que as aves alimentadas com as dietas contendo $22 \%$ PB e formulada com aminoácidos totais e com $20 \%$ PB formulada com aminoácidos digestíveis. É possível trabalhar com dietas contendo menor nível protéico (20\% PB) sem afetar o desempenho das aves, quando a dieta for formulada com aminoácidos digestíveis.

Palavras-chave: aminoácidos digestíveis, frangos de corte, nível protéico, nutrição.

\section{ABSTRACT}

One experiment was conducted to study the reduction of protein level, through formulation based in digestible amino acids, using broilers in the initial phase. Eight hundred one-day-old male chicks, Cobb, were weighted and distributed in a random design, envolving four treatments $(22 \%, 20 \%$ and $18 \%$ crude protein with digestible aminoacids and one control treatment with $22 \%$ crude protein based on total amino acids), envolving 4 replications of 50 birds each. Data from weight gain, feed intake and feed conversion were collected. When broilers were fed control diet, the same weight gain and feed conversion were obtained when compared with birds fed $22 \%$ crude protein and total amino acids and $20 \%$ crude protein formulated on digestible amino acids. It is possible to work diets with less protein level $(20 \%$ crude protein) without affecting the performance when diet is formulated based on digestible amino acids.

Key words: broilers, digestible amino acids, nutrition, proteinlevel.

\section{INTRODUÇÃO}

Uma importante função da produção animal é fornecer alta qualidade protéica para a alimentação humana. Para cumprir este papel, os próprios animais requerem alta qualidade protéica em correta proporção nas dietas.

Durante muitos anos, as rações para aves foram formuladas para satisfazer as necessidades de proteína bruta dos animais. Com o crescente desenvolvimento da indústria de aminoácidos sintéticos, os nutricionistas puderam passar a formular as rações com o objetivo de satisfazer as necessidades específicas de aminoácidos essenciais. Hoje, a suplementação de aminoácidos sintéticos nas rações é uma prática incorporada na rotina das fábricas de rações para aves. Como conseqüência, os níveis de PB das dietas tiveram uma considerável redução nas formulações. Entretanto, a questão que ainda permanece é o quanto a proteína bruta pode ser reduzida sem prejudicar o desempenho destes animais.

Dados de pesquisa (ALETOR et al., 2000; BREGENDAHL et al.,2002) confirmam que o excesso

${ }^{1}$ Docente da Universidade de São Paulo (USP), Faculdade de Zootecnia e Engenharia de Alimentos (FZEA), Departamento Zootecnia, Av. Duque de Caxias Norte, 225, 13635-900, Pirassununga, SP. E-mail: lfaraujo@usp.br. Autor para correspondência. ${ }^{2}$ Docente do Departamento de Zootecnia, Faculdade de Ciências Agárias e Veterinárias (FCAV), Universidade Estadual Paulista

(UNESP), Jaboticabal, SP.

${ }^{3}$ Aluno do Curso de Pós-graduação em Zootecnia, UNESP, Jaboticabal, SP. 
de proteína bruta consumido deprecia o desempenho das aves, eleva o custo de formulação da dieta, incrementa o calor metabólico e contribui para o aumento na excreção de nitrogênio. Alguns trabalhos (CHENG et al., 1997 a, b; CHENG et al., 1999) demonstram que o excesso de proteína na dieta aumenta as exigências das aves em aminoácidos limitantes.

RANGEL-LUGO et al. (1994) avaliaram a resposta de frangos de corte alimentados com dietas contendo $20 \%$ e $25 \%$ de proteína bruta na dieta sobre as exigências de aminoácidos na fase inicial. Os autores relataram que o aumento do nível protéico da dieta aumentou as exigências nutricionais de treonina. HUSSEIN et al., (2001) trabalharam com dietas variando de $17,5 \%$ a $23 \%$ de proteína bruta para frangos de corte na fase inicial e observaram uma diminuição no desempenho das aves. BREGENDAHL et al. (2002) reduziram o nível protéico da dieta inicial de $23 \%$ para $19 \%$ e observaram uma diminuição do desempenho das aves, relatando que frangos de corte nesta fase de desenvolvimento são mais sensíveis a variações nos níveis protéicos da dieta. Entretanto (SUMMERS et al., 1992; DESCHEPPER \& DE GROOTE, 1995) demonstraram ser possível reduzir o nível protéico da dieta sem prejudicar o desempenho dos animais.

No entanto, devido ao alto incremento calórico da proteína, parece não ser adequada a redução do nível protéico da dieta para frangos de corte na fase inicial quando os mesmos são criados em condições de baixa temperatura (MUSHARAF \& LATSHAW, 1999).

Entretanto, PENZ (2001) justifica a utilização de uma dieta com maior nível protéico na fase inicial, principalmente em ambientes com temperatura abaixo da zona de conforto térmico das aves, pois nesta fase, os frangos passam por mudanças anatômicas e fisiológicas que os tornam mais sensíveis às suas necessidades nutricionais e, desta forma, as perdas sofridas pela ave neste período, podem comprometer o seu desempenho final.

A formulação de dietas com base em aminoácidos digestíveis, embora tenha sido bastante trabalhado nos últimos tempos em nível experimental, tem sido um conceito distante da realidade de sua utilização na prática. Vários autores têm demonstrado as vantagens de sua utilização. BAKER \& HAN (1994), fornecendo dietas formuladas com aminoácidos digestíveis, segundo as recomendações de Illinóis, e com aminoácidos totais, de acordo com recomendações do NRC (1984) e NRC (1994) no período de 1 a 21 dias de idade observaram melhor desempenho em aves alimentadas com a dieta formulada com aminoácidos digestíveis. Segundo PACK (1995), não restam dúvidas de que as formulações de aminoácidos devem ser expressos em digestíveis ao invés de totais. ARAUJO et al. (2002) conduziram dois experimentos avaliando dietas formuladas à base de milho e soja, com base em aminoácidos digestíveis e totais no período de 1 a 21 dias de idade. Os autores encontraram melhor desempenho com aves alimentadas com as dietas formuladas com aminoácidos digestíveis.

O objetivo deste trabalho foi o de avaliar a redução do nível protéico da dieta, através da formulação baseada em aminoácidos digestíveis, sobre o desempenho de frangos de corte na fase inicial de criação.

\section{MATERIAL E MÉTODOS}

Um experimento foi conduzido no aviário experimental da Faculdade de Ciências Agrárias e Veterinárias, UNESP, Campus de Jaboticabal, com o objetivo de avaliar a redução do nível protéico da dieta sobre o desempenho de frangos de corte no período de 1 a 21 dias de idade. Foram utilizados 800 pintos machos, da linhagem Cobb, distribuídos em um delineamento inteiramente casualizado, com 4 tratamentos, sendo: 3 dietas com níveis decrescentes de proteína bruta $(22 \%, 20 \%$ e $18 \%$, formuladas com aminoácidos digestíveis) e 1 tratamento testemunha com a dieta com $22 \%$ de proteína bruta e formulada com aminoácidos totais. As recomendações nutricionais utilizadas foram preconizadas por ROSTAGNO et al., (2000). Foram utilizadas 4 repetições por tratamento, com 50 aves cada. As dietas apresentaram a relação ideal de aminoácidos (metionina, metionina+cistina e treonina) conforme mostra a tabela 1. Considerou-se como dieta referência, a dieta contendo $22 \%$ de proteína bruta formulada com aminoácidos digestíveis.

Por ocasião do recebimento, as aves foram pesadas, selecionadas e distribuídas aleatoriamente entre os tratamentos. Todas receberam água e alimentação à vontade. Foi utilizado um galpão de alvenaria, com 30 x 6,65m, cumeeira com orientação leste-oeste, pé-direito de 3,2m, sem lanternim, coberto com telhas cimento amianto, contendo 32 boxes de 2,1 x 2,5m cada, com uma mureta de alvenaria de $0,40 \mathrm{~m} \mathrm{e}$ tela de arame, protegido por cortina de plástico amarela, com sistema móvel de catraca para sua movimentação no controle do ambiente interno do mesmo. Os boxes tinham como cama a casca de arroz e foram equipados com campânula, para aquecimento dos pintos, comedouros tipo tubular infantil e bebedouros de 
Tabela 1 - Perfis de aminoácidos expressos como percentagem de lisina.

\begin{tabular}{lc}
\hline Aminoácido & $\%$ Lisina \\
\hline Lisina & $100(1,18)$ \\
Metionina & $39(0,46)$ \\
Met+Cis & $71(0,84)$ \\
Treonina & $59(0,70)$ \\
\hline
\end{tabular}

pressão. A retirada dos equipamentos infantis foi feita a partir do $5^{\circ}$ dia de criação, sendo que já no $3^{\circ}$ dia iniciou-se a introdução dos equipamentos adultos. $\mathrm{O}$ controle do aquecimento, bem como o manejo das cortinas foi de acordo com a necessidade das aves. Como características de desempenho, foram avaliados o ganho de peso, consumo de ração e conversão alimentar.

As rações experimentais foram formuladas à base de milho, farelo de soja, glúten de milho, óleo de soja, fosfato bicálcico, calcário calcítico, sal comum, aminoácidos sintéticos e suplementos vitamínico e mineral (tabela 2). O nível de lisina adotado foi o preconizado por ROSTAGNO et al. (2000).

As análises estatísticas foram realizadas utilizando-se o programa SAS - Statistic Analisys System (SAS, 1986). Para comparação de médias foi utilizado o Teste de Tukey ao nível de $5 \%$.

\section{RESULTADOS E DISCUSSÃO}

Os efeitos da redução do nível protéico da dieta sobre o desempenho de frangos de corte na fase inicial encontram-se na tabela 3. Quando as aves foram alimentadas com a dieta referência, formulada para conter $22 \%$ PB e com base em aminoácidos digestíveis, obtiveram, estatisticamente $(\mathrm{P}>0,05)$ mesmo ganho de peso e conversão alimentar que as aves alimentadas com as dietas contendo $22 \%$ PB e formulada com aminoácidos totais e com $20 \%$ PB formulada com aminoácidos digestíveis, já que o consumo de ração não foi alterado pelos tratamentos estudados. Estes resultados demonstraram ser possível diminuir o nível protéico da dieta na fase inicial desde que a formulação seja com base em aminoácidos digestíveis.

Uma série de trabalhos demonstraram que a redução do teor de proteína bruta da dieta não afeta o consumo de ração (PINCHASOV et al., 1990; SUMMERS, et al., 1992; FERGUSON et al., 1998), concordando com os resultados encontrados neste experimento. FARIA FILHO (2002) trabalhando com dietas contendo $18.5 \%, 20 \%$ e $21.5 \%$ não encontrou diferenças para consumo de ração. Segundo
GONZALES (2002), o consumo de ração não é decorrente apenas da quantidade de proteína bruta da dieta mas também da sua qualidade, ou seja, da concentração e do balanceamento dos aminoácidos. Os trabalhos de COSTA et al. (2001) e de BREGENDHAL et al. (2002) discordam dos resultados deste experimentos, pois observaram um aumento no consumo de ração de frangos de corte machos quando houve uma diminuição do nível protéico da dieta.

COLNAGO et al. (1991) compararam uma dieta com 23\% PB com dietas com menor teor de proteína, suplementadas com aminoácidos sintéticos, para manter metionina, lisina, arginina, treonina, triptofano, isoleucina e valina nos níveis recomendados para frangos de corte, de 1 a 21 dias de idade, (NRC, 1984). Os resultados mostraram uma diminuição linear no consumo de ração, ganho de peso e na eficiência alimentar com a diminuição da PB. Com base nos resultados, os autores concluíram que é necessário um nível mínimo de proteína intacta para não comprometer o desempenho das aves.

PARR \& SUMMERS (1991) conduziram uma série de experimentos com frangos de corte, de 7 a 21 dias de idade, em que foi formulada uma dieta controle com $23 \%$ de proteína bruta, à base de milho e farelo de soja, respectivamente. A partir desta ração, foram formuladas dietas em que os níveis de proteína bruta foram reduzidos até $16,5 \%$ e com a suplementação de aminoácidos sulfurados para atingir as suas exigências. Os autores não encontraram diferença no desempenho das aves.

COLNAGO \& JENSEN (1992) conduziram um experimento em que os níveis de proteína bruta foram diminuídos de 23 para 20 e $17 \%$, suplementados com aminoácidos sintéticos e uma poliamida (putrescina). Os resultados mostraram um pior desempenho das aves para ganho de peso e eficiência alimentar com a diminuição da PB da dieta. A suplementação de putrescina não influenciou o desempenho.

WALDROUP (2000) avaliou níveis protéicos $(16 \%$ a $22 \%)$ para frangos de corte, no período de 1 a 21 dias, e demonstrou que dietas com níveis de proteína bruta abaixo de $20 \%$ afetam negativamente o desempenho das aves, diminuindo o ganho de peso e piorando a conversão alimentar. Da mesma forma encontrada neste experimento, os resultados descritos por FARIA FILHO (2002) também demonstraram uma diminuição no ganho de peso e piora na conversão alimentar quando o nível protéico da dieta reduziu de $21,5 \%$ para $18,5 \%$. Os resultados encontrados por PINCHASOV et al. (1990), FERGUSON etal. (1998), COSTAetal. (2001), HUSSEIN 
Tabela 2 - Composição percentual das dietas experimentais.

\begin{tabular}{|c|c|c|c|c|}
\hline \multirow[t]{2}{*}{ Ingredientes } & \multicolumn{4}{|c|}{ Dietas experimentais } \\
\hline & 18 AAD* & $20 \mathrm{AAD}$ & $22 \mathrm{AAD}$ & $22 \mathrm{AAT}$ \\
\hline Milho & 66,14 & 59,98 & 54,29 & 54,51 \\
\hline Farelo de soja & 25,13 & 30,66 & 35,25 & 34,73 \\
\hline Glúten de milho & 1,50 & 1,50 & 2,15 & 2,50 \\
\hline Óleo de soja & 2,31 & 3,28 & 4,05 & 3,95 \\
\hline Fosfato bicálcico & 1,98 & 1,94 & 1,91 & 1,92 \\
\hline Calcário calcítico & 1,11 & 1,08 & 1,06 & 1,06 \\
\hline Sal & 0,40 & 0,41 & 0,39 & 0,39 \\
\hline Metionina & 0,30 & 0,25 & 0,20 & 0,20 \\
\hline Lisina & 0,50 & 0,34 & 0,21 & 0,24 \\
\hline Treonina & 0,13 & 0,06 & 0,00 & 0,00 \\
\hline Sup. Vit/Mineral & 0,50 & 0,50 & 0,50 & 0,50 \\
\hline \multirow[t]{2}{*}{ Total } & 100,00 & 100,00 & 100,00 & 100,00 \\
\hline & \multicolumn{4}{|c|}{ Análise calculada } \\
\hline $\mathrm{EM}(\mathrm{kcal} / \mathrm{kg})$ & 3.100 & 3.100 & 3.100 & 3.100 \\
\hline $\mathrm{PB}(\%)$ & 18,00 & 20,00 & 22,00 & 22,00 \\
\hline $\mathrm{Ca}(\%)$ & 1,00 & 1,00 & 1,00 & 1,00 \\
\hline Pdisp (\%) & 0,47 & 0,47 & 0,47 & 0,47 \\
\hline Sódio (\%) & 0,20 & 0,20 & 0,20 & 0,20 \\
\hline Lis dig (\%) & 1,18 & 1,18 & 1,18 & 1,20 \\
\hline Lis $(\%)$ & 1,29 & 1,30 & 1,32 & 1,31 \\
\hline Met dig (\%) & 0,46 & 0,46 & 0,46 & 0,50 \\
\hline Met $(\%)$ & 0,62 & 0,60 & 0,58 & 0,51 \\
\hline Met+cis dig $(\%)$ & 0,84 & 0,84 & 0,84 & 0,84 \\
\hline Met+cis $(\%)$ & 0,95 & 0,95 & 0,96 & 0,93 \\
\hline Tre dig (\%) & 0,70 & 0,70 & 0,70 & 0,72 \\
\hline $\operatorname{Tre}(\%)$ & 0,84 & 0,85 & 0,86 & 0,83 \\
\hline
\end{tabular}

Suplemento Vitamínico/Mineral (kg de dieta): Vit A - 1.500UI; Vit D3 500UI; Vit E - 20mg; Vit K3 - 0,49mg; Vit B1 - 2mg; Vit B2 - 6,60mg; Vit B12 - 20mcg; Pantotenato de Cálcio - 10mg; Niacina - 100mg; Ác. Fólico 0,50mg; Promotor de crescimento - 50ng; Colina - 250mg; Cobre - 75mg; Iodo - 1,25mg; Selênio - 0,25mg; Manganês - 120mg; Zinco - 100mg; Ferro - 50mg; Coccidicida - 125mg; antioxidante - 0,63mg; Veículo q. s. p. $1.000 \mathrm{~g}$.

* AAD - Aminoácidos digestíveis; AAT - Aminoácidos totais.

Tabela 3 - Desempenho de frangos de corte sob crescentes níveis protéicos no período de 1 a 21 dias de idade.

\begin{tabular}{lccc}
\hline Tratamentos & \multicolumn{2}{c}{ Caracteristicas } \\
\hline & $\begin{array}{c}\text { Ganho de } \\
\text { peso }(\mathrm{g})\end{array}$ & $\begin{array}{c}\text { Consumo de } \\
\text { ração }(\mathrm{g})\end{array}$ & $\begin{array}{c}\text { Conversão } \\
\text { alimentar(g/g) }\end{array}$ \\
Proteína bruta (\%) & & $1.124 \mathrm{a}$ & $1,57 \mathrm{a}$ \\
$18 \mathrm{AAD} *$ & $715 \mathrm{~b}$ & $1.080 \mathrm{a}$ & $1,48 \mathrm{ab}$ \\
$20 \mathrm{AAD}$ & $729 \mathrm{ab}$ & $1.122 \mathrm{a}$ & $1,46 \mathrm{~b}$ \\
$22 \mathrm{AAD}$ & $771 \mathrm{a}$ & $1.088 \mathrm{a}$ & $1,50 \mathrm{ab}$ \\
$22 \mathrm{AAT}$ & $728 \mathrm{ab}$ & 2,44 & 3,55 \\
$\mathrm{CV}(\%)$ & 3,10 & & \\
\hline
\end{tabular}

Dentro da mesma coluna, médias seguidas de mesma letra não diferem entre si pelo teste de Tukey $(\mathrm{p}>0,05)$.

* AAD - Aminoácidos digestíveis; AAT - Aminoácidos totais. et al. (2001) e BREGENDAHL et al. (2002) confirmam estes resultados. Por outro lado, diferentemente do que foi encontrado neste trabalho os estudos realizados por PARR \& SUMMERS (1991), SUMMERS et al. (1992) e DESCHEPPER \& DE GROOTE (1995), indicaram ser possível reduzir o nível de proteína bruta da dieta sem afetar o consumo de ração e a conversão alimentar das aves.

\section{CONCLUSÃO}

De acordo com as condições em que o experimento foi conduzido, pode-se concluir que, na fase inicial de criação de frangos de corte, a formulação de dietas com base em aminoácidos digestíveis permite uma redução no desperdício de proteína.

\section{AGRADECIMENTOS}

À FAPESP pelo suporte financeiro (Processo 98/ 06355-3).

\section{REFERÊNCIAS BIBLIOGRÁFICAS}

ALETOR, V.A. et al. Low-protein amino acidsupplemented diets in broiler chickens: effects on performance, carcass characteristics, whole body composition and efficiencies of nutrient utilisation. Journal of the Science of Food and Agriculture, v.80, p.547-554, 2000.

ARAUJO, L.F. et al. Diferentes critérios de formulação de rações para frangos de corte no período de 1 a 21 dias de idade. Revista Brasileira de Zootecnia, v.4, p.195-202, 2002.

BAKER, D. H.; HAN, Y. Ideal amino acid profile for chicks during the first three weeks posthatching. Poultry Science, v.73, p.1441-1447, 1994.

BREGENDAHL, K.; SELL, J.L.; ZIMMERMAN, D.R. Effect of low-protein diets on growth performance and body composition of broiler chicks. Poultry Science, v.81, p.1156-1167, 2002.

CHENG, T.K.; HAMRE, M.L.; COON, C.N. Effect of environmental temperature, dietary protein and energy levels on broiler performance. Journal of Applied Poultry Research, v.6, p.1-17, 1997a.

CHENG, T.K.; HAMRE, M.L.; COON, C.N. Responses of broilers to dietary protein levels and amino acid supplementation to low protein diets at various environmental temperatures. Journal of Applied Poultry Research, v.6, p.18-33, 1997b.

CHENG, T.K.; HAMRE, M.L.; COON, C.N. Effect of constant and cyclic environmental temperatures, dietary 
protein and amino acids levels on broiler performance. Journal of Applied Poultry Research, v.8, p.426-439, 1999.

COLNAGO, G.L.; JENSEN, L.S. Putrescine effects on performance of male broiler chicks fed low-protein diets supplemented with essential amino acids. Poultry Science, v.71, p.211-214, 1992.

COLNAGO, G.L.; PENZ JR, A.M.; JENSEN, L.S. Effect of response of starting broilers chicks to incremental reduction in intact protein on performance during the grower phase. Poultry Science, v.70, p.153-158, 1991.

COSTA, F.G.P. et al. Níveis dietéticos de proteína bruta para frangos de corte de 1 a 21 e 22 a 42 dias de idade. Revista Brasileira de Zootecnia, v.30, p.1498-1505, 2001.

DESCHEPPER, K.; DE GROOTE, G. Effect of dietary protein, essential and non essential amino acids on the performance and carcass composition of male broiler chickens. British Poultry Science, v.36, p.229-245, 1995.

FARIA FILHO, D.E. Efeito de dietas com baixo teor protéico, formuladas usando o conceito de proteína ideal, para frangos de corte criados em temperaturas fria, termoneutra e quente. 2002. 85f. Dissertação (Mestrado em Zootecnia) - Curso de Pós-graduação em Zootecnia, Faculdade de Ciências Agrárias e Veterinárias UNESP - Jaboticabal.

FERGUSON, N.S. et al. The effect of dietary protein on growth, ammonia concentration, and litter composition in broilers. Poultry Science, v.77, p.1481-1486, 1998

GONZALES, E. Ingestão de alimentos: mecanismos regulatórios. In: MACARI, M.; FURLAN, R.L.; GONZALES, E. (Ed.). Fisilogia aviária aplicada a frangos de corte. 2.ed. Jaboticabal : FUNEP, 2002. p.187-199.

HUSSEIN, A.S. et al. Effect of low protein diets with amino acid supplementation on broiler growth. Journal of Applied Poultry Research, v.10, p.654-362, 2001

MUSHARAF, N.A ; LATSHAW, J.D. Heat increment as affected by protein and amino acid nutrition. World's Poultry Science, v.55, p.233-240, 1999.
NRC - National Research Council. Nutrient requirements of poultry. 8.rev. ed. Washington : National Academy, 1984. 75p.

NRC - National Research Council. Nutrient requirements of poultry. 9.rev ed. Washington : National Academy, 1994. 96p.

PACK, M. Proteína ideal para frangos de corte. Conceitos e posição atual. In: CONFERÊNCIA APINCO DE CIÊNCIA E TECNOLOGIA AVÍCOLAS, 1995, Curitiba. Anais... Curitiba: FACTA, 1995. p.95-110.

PARR, J.F.; SUMMER, J.D. The effect of minimizing amino acid excesses in broiler diets. Poultry Science, v.70, p.1540$1549,1991$.

PENZ JR, A.M. Recentes avanços na nutrição de frangos de corte. In: ENCONTRO TÉCNICO SOBRE AVICULTURA DE CORTE DA REGIÃO DE DESCALVADO, 5., 2001, Descalvado, SP. Anais... Descalvado : Instituto Biológico, 2001. p.15-46.

PINCHASOV, Y.; MENDONÇA, C.X.; JENSEN, L.S. Broiler chick response to low protein diets supplemented with synthetic amino acids. Poultry Science, v.69, p.1950-1955, 1990.

RANGEL-LUGO, M.; SU, C.L.; AUSTIC, R.E. Threonine requirement and threonine imbalance in broiler chicks. Poultry Science, v.73, p.670-681, 1994.

ROSTAGNO, H.S. et al. Composição de alimentos e exigências nutricionais de aves e suínos: tabelas brasileiras para aves e suínos. Viçosa : UFV, 2000. 141p.

SAS Institute - SAS User's Guide: statistics. Cary, NC : SAS Institute, 1986.

SUMMERS, J.D.; SPRATT, D.; ATKINSON, J.L. Broiler weight gain and carcass composition when fed diets varying in amino acid balance, dietary energy and protein level. Poultry Science, v.71, p.263-273, 1992.

WALDROUP, P.W. Nuritional approaches to minimizing nitrogen and phosphorus excretion in broilers. In: SIMPÓSIO SOBRE MANEJO E NUTRIÇÃO DE AVES E SUÍNOS, 2000, Campinas, SP. Anais... Campinas : CBNA, 2000. p.82-98. 